\title{
Association of Diabetes Mellitus and Insulin Resistant in Polycystic Ovarian Syndrome (PCOS) Women in Kerala
}

\author{
Arghya Sur ${ }^{1}$, Arindam Basu ${ }^{2}$, Hemontika Chakraborty ${ }^{2}$ \\ ${ }^{I}$ Department of Physiology. Kerala Medical College and Hospital, Mangode, Cherpulassery, Palakkad Dist, \\ Kerala, India \\ ${ }^{2}$ Department of Biochemistry, Kerala Medical College and Hospital, Mangode, Cherpulassery, Palakkad Dist,, \\ Kerala, India
}

\begin{abstract}
:
Objective: To determine the association of Insulin Resistance (IR) characteristics; as a predictor of diabetes mellitus and hormonal disturbance in patients with PCOS.

Material and methods:

Design: Prospective study

Setting: Kerala Medical college and Hospital, Mangode, Cherpulassery, Palakkad Dist,, Kerala

Subjects: 51 females with PCOS diagnosed by Rotterdam criteria were enrolled.

Methods: Patients with PCOS were examined in detail for anthropometry, blood pressure, hirsutism and acanthosis nigricans and other markers of insulin resistance. Biochemical estimation such as fasting glucose and fasting lipid profile with an oral GTT were done. Analysis of TSH, FSH, LH, DHEA-S, Testosterone, cortisol were done by radioimmunoassay.
\end{abstract}

Results: 51 females with PCOS were enrolled for the study of which (78.4\%) 40 were having IR and among those $(72.5 \%) 29$ had diabetes. $P<0.001$, which is statistically very high significant

Conclusions: IR characteristics could emerge as a marker of diabetes mellitus in PCOS subjects in Kerala state population

Key words: PCOS, Diabetes.

\section{Introduction}

Polycystic Ovarian Syndrome (PCOS) is referred to some times as Sclerocystic Ovarian Disease, SteinLeventhal Syndrome and Polycystic Ovarian Disease (PCOD). PCOS is a complex, heterogeneous, polygenic endocrine disorder in women of reproductive age and is considered as a multifactorial reproductive, cosmetic and metabolic problem. The etiology of PCOS is not well understood and its pathophysiological and molecular basis is still a puzzle. PCOS is likely to be the result of a number of both genetic and environmental factors. Some of the contributing factors to PCOS also include a low level of chronic inflammation in the body and fetal exposure to male hormones. However, androgen excess and insulin resistance leading to hyperinsulinemia are considered to be the basic defects in PCOS that was described way back in 1921 by Archard \& Theirs as "diabetes of bearded women"1.

The world wide prevalence of PCOS syndrome is $6-10 \%$ and in its "classical" form may affect $5-7 \%$ of women ${ }^{2}$. PCOS is quite common in Asian population. A high prevalence of up to $35 \%$ is reported for the Indian women and the incidence and prevalence of PCOS in overweight and obese women is greater than $20 \%{ }^{3}$. Women with PCOS are at a higher risk for a number of illnesses, including high blood pressure, diabetes, heart disease and other cardiovascular problems and cancer of the uterus, ovary and breast ${ }^{4}$.

PCOS also presents with a variety of biochemical abnormalities ${ }^{5}$. The most consistent abnormality is hypersecretion of androgens. Because of the high degree of heterogeneity of PCOS, it is suggested best to consider PCOS as increased androgens clinically (acne, excessive hair on face, abdomen, or thinning of scalp hair) or in the blood (total or free testosterone, DHEAS), with oligo-ovulation (cycles greater the every 35 days, low mid-luteal progesterone, monophasic basal body temperature.

Objective:- To determine the IR characteristics; as a predictor of diabetes mellitus and hormonal disturbance in patient with PCOS. 


\section{Material and Methods}

Subjects:- 51 females with PCOS diagnosed by Rotterdam criteria were enrolled. Methods:

Patient with PCOS were examined in detail for anthropometry, blood pressure, hirsutism and acanthosis nigricans and other markers insulin resistance. Biochemical estimation such as fasting glucose and fasting lipid profile with a oral GTT were done. Analysis of TSH (vide Table 5), FSH (vide Table 4), LH (vide table 3), DHEA-S (vide Table 1), Testosterone (vide Table 2), Cortisol (vide Table 6) were done.

\section{Results \& Discussion:}

51 women with PCOS were enrolled for the study of which (78.4\%) 40 were having IR and among them $(72.5 \%) 29$ had diabetes, $\mathrm{P}<0.001$, which is statistically very high significant. However we have found an altered ratio of mean value of LH:FSH (2:1) (vide table 3 and 4). Family history of diabetes present in 100\% cases in patient with acanthosis nigricans. While $57 \%$ in without acanthosis nigricans (vide Table 8 ).

\section{Conclusions}

PCOS patients with acanthosis nigricans were found to have a very high prevalence of diabetes. Hence IR charectaristics could emerge as a marker of diabetes mellitus in PCOS subjects in Kerala.

\section{References:}

[1]. Archard C, Theirs J. Le virilisme pilaire et son asson a 1'insuffisance glycolitique. Bull Acad Natl Med (Paris) 1921; 86:51 -64.

[2]. Fauser B, Tarlatzis B, Chang J. et al. 2003 ASRM/ESHRE consensus document. Fertil Steril. 2004; 18: 19-25.

[3]. Alvarez-Blasco F, Botella-Carretero JI, san Millan JL et al. Prevalence and characterstics of the polycystic ovary syndrome in overweight and obese women. Arch Intrn Med 2006; 166: 2081-2086.

[4]. Daniilidis A, Dinas K. Long term health consequences of polycystic ovarian syndrome: a review analysis. Hippokratia 2009; 13: 90-92.

[5]. Kashar-Miller M, Azziz R. Heritability and the risk of developing androgen excess. J Steroid Biochem Mol Biol 1999; 69 : 261 -268.

\section{Tables}

Table 1: DHEA-S

\begin{tabular}{|l|r|r|rr|}
\hline \multicolumn{1}{|c|}{ GROUP } & Mean & Std. Deviation & \multicolumn{2}{|c|}{ Z } \\
\hline Without Acanthosis & 217.1200 & 156.8760 & & .200 \\
Nigricans and DM & 272.3750 & 127.28140 & $\mathrm{P}=0.826$ \\
With Acanthosis & & & & \\
Nigricans with DM & & & & \\
\hline
\end{tabular}

Table 3: LH

\begin{tabular}{|l|r|r|r|}
\hline \multicolumn{1}{|c|}{ GROUP } & \multicolumn{1}{|c|}{ Mean } & \multicolumn{1}{|c|}{ Std. Deviation } & \multicolumn{1}{c|}{ Z } \\
\hline Without Acanthosis Nigricans and DM & 9.2886 & 5.50828 & .65800 \\
With Acanthosis Nigricans with DM & 10.3575 & 7.83627 & $\mathrm{P}=0.51$ \\
& & & \\
\hline
\end{tabular}

Table 4: FSH

\begin{tabular}{|c|c|c|c|}
\hline GROUP & Mean & Std. Deviation & $\mathrm{Z}$ \\
\hline $\begin{array}{l}\text { Without Acanthosis Nigricans and DM } \\
\text { With Acanthosis Nigricans with DM }\end{array}$ & $\begin{array}{l}4.9357 \\
5.6250\end{array}$ & $\begin{array}{l}2.19778 \\
1.80509\end{array}$ & $\begin{array}{r}.46100 \\
\mathrm{P}=0.645\end{array}$ \\
\hline
\end{tabular}


Table 5: TSH

\begin{tabular}{|l|r|r|r|}
\hline \multicolumn{1}{|c|}{ GROUP } & Mean & \multicolumn{1}{|c|}{ Std. Deviation } & \multicolumn{1}{c|}{$\mathrm{Z}$} \\
\hline Without Acanthosis Nigricans and DM & 1.100 & .7789 & .2800 \\
With Acanthosis Nigricans with DM & 2.45 & 2.718 & $\mathrm{P}=0.812$ \\
\hline
\end{tabular}

Table 6: CORTISOL

\begin{tabular}{|l|r|r|r|}
\hline \multicolumn{1}{|c|}{ GROUP } & Mean & Std. Deviation & \multicolumn{1}{|c|}{$\mathrm{Z}$} \\
\hline $\begin{array}{l}\text { Without Acanthosis Nigricans } \\
\text { and DM }\end{array}$ & 9.3633 & 6.10707 & .65000 \\
$\begin{array}{l}\text { With Acanthosis Nigricans with } \\
\text { DM }\end{array}$ & 17.1628 & 1.09267 & $\mathrm{P}=0.516$ \\
\hline
\end{tabular}

Table 7: Dyslipidimia

\begin{tabular}{|c|l|r|r|r|}
\hline \multicolumn{2}{|c|}{} & \multicolumn{2}{|c|}{ GROUP } \\
\cline { 3 - 5 } & $\begin{array}{c}\text { Without Acanthosis } \\
\text { Nigricans and DM }\end{array}$ & $\begin{array}{c}\text { With Acanthosis } \\
\text { Nigricans with } \\
\text { DM }\end{array}$ & Total \\
\hline Yes & \begin{tabular}{l} 
Count \\
\multicolumn{2}{|c|}{}
\end{tabular} & 3 & 11 & 14 \\
& $\%$ & $60.0 \%$ & $84.6 \%$ & $77.8 \%$ \\
\hline No & Count & 2 & 2 & 4 \\
& $\%$ & $40.0 \%$ & $15.4 \%$ & $22.2 \%$ \\
\hline Total & Count & 5 & 13 & 18 \\
& $\%$ & $100.0 \%$ & $100.0 \%$ & $100.0 \%$ \\
\hline
\end{tabular}

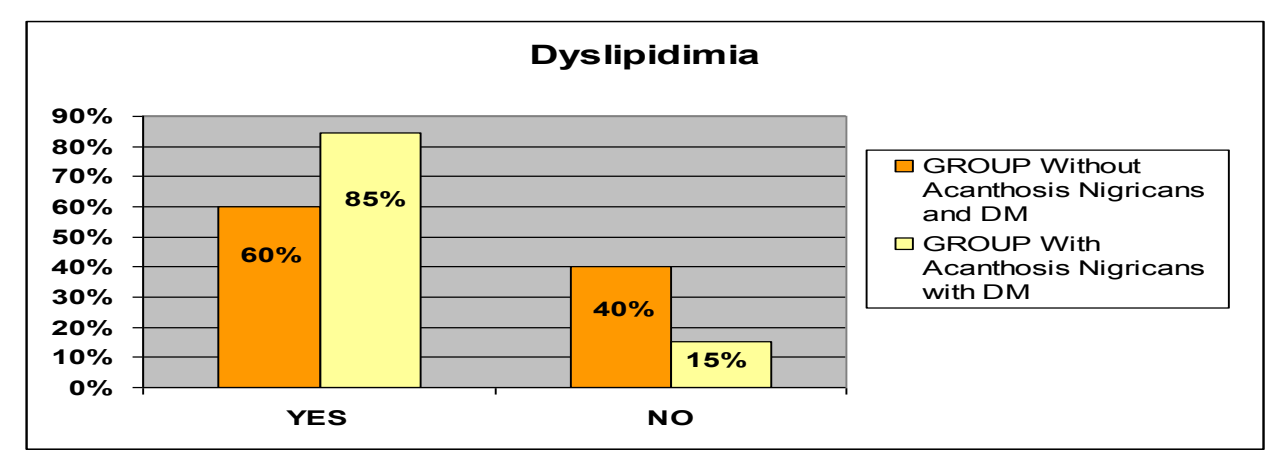

Table 8: Family History of DM

\begin{tabular}{|c|c|c|c|c|}
\hline & & \multicolumn{2}{|c|}{ GROUP } & \multirow[b]{2}{*}{ Total } \\
\hline & & $\begin{array}{l}\text { Without Acanthosis } \\
\text { Nigricans and DM }\end{array}$ & $\begin{array}{c}\text { With Acanthosis } \\
\text { Nigricans with DM }\end{array}$ & \\
\hline Yes & $\begin{array}{l}\text { Count } \\
\%\end{array}$ & $\begin{array}{r}1 \\
14.3 \%\end{array}$ & $\begin{array}{r}36 \\
100.0 \%\end{array}$ & $\begin{array}{r}1 \\
2.6 \%\end{array}$ \\
\hline No & $\begin{array}{l}\text { Count } \\
\% \\
\end{array}$ & $\begin{array}{r}6 \\
85.7 \% \\
\end{array}$ & $\begin{array}{r}0 \\
.0 \% \\
\end{array}$ & $\begin{array}{r}37 \\
97.4 \% \\
\end{array}$ \\
\hline Total & $\begin{array}{l}\text { Count } \\
\%\end{array}$ & $\begin{array}{r}7 \\
100.0 \%\end{array}$ & $\begin{array}{r}36 \\
100.0 \%\end{array}$ & $\begin{array}{r}38 \\
100.0 \%\end{array}$ \\
\hline
\end{tabular}

